\title{
Concordancias estructurales y otros aspectos relevantes de la regulación del teletrabajo en Argentina y España
}

\section{Structural concordances and other relevant aspects of telework regulation in Argentina and Spain}

\author{
Juan Facundo Temperoni \\ Relator Letrado \\ Suprema Corte de Justicia de la Provincia de Buenos Aires \\ ORCID ID: 0000-0001-7502-8639
}

Recibido: $18 / 11 / 2020$

Aceptado: $1 / 7 / 2021$

doi: https://doi.org/10.20318/labos.2021.6486
Resumen: Ponderando sus principales antecedentes y el particular contexto sanitario en el que han sido concebidas, el presente análisis procura brindar una descripción del núcleo de coincidencias que se registran en las recientes regulaciones del teletrabajo concebidas en la Argentina y España. Con ese objetivo, mediante el cotejo pertinente, y sin soslayar algunos de sus rasgos distintivos, se enun- cian las diferentes aristas que en común exhiben los dos regímenes destinados a normar la nueva forma de organización del trabajo, en lo cardinal, aquellos derechos y directrices fundamentales como son la igualdad en reflejo con las personas que trabajan presencialmente, la voluntariedad, reversibilidad y des- conexión digital, entre otros.

Palabras clave: Teletrabajo, trabajo a distancia, regulación, Argentina, España.

Abstract: Considering their main antecedents and the particular healthcare context in which they have been conceived, this analysis attempts to provide a description of the nucleus of coincidences that are recorded in the recent telework regulations conceived in Argentina and Spain. With that objective, by means of the pertinent collation, and without ignoring some of its distinctive features, the different edges that the two regimes exhibit in common are enunciated, destined to regulate the new form of work organization, in the cardinal, those fundamental rights and guidelines such as equality in reflection with people who work in person, voluntariness, reversibility and digital disconnection, among others.

Keywords: Telework, remote work, regulation, Argentina, Spain.

*jftemperoni@gmail.com 


\section{Introducción. Antecedentes}

Recientemente, tanto la Argentina por medio de la Ley 27.555 llamada "Régimen legal del contrato de Teletrabajo" (publicada en su Boletín Oficial el día 14/08/2020) y su reglamentación por el Decreto 27/2021 (publicado en su Boletín Oficial el día 20/01/2021) como Espańa por conducto del Real Decreto-ley 28/2020 (publicado en su Boletín Oficial el día 23/09/2020) y su posterior recepción parlamentaria -sin cambios estructurales- por la Ley 10/2021 "de trabajo a distancia" (pub. B.O.E. de 9/07/2021), lograron regular el teletrabajo, figura que -es sabido- remite a una moderna forma de organizar remotamente las labores en relación de dependencia. En el caso español, anticipamos, se lo legisló a partir de la noción de trabajo a distancia y en su condición de "subespecie" comprendida en este último.

Con anterioridad -siempre limitados al ámbito de las relaciones de trabajo privadas- no se verificaba en el país latinoamericano normativa alguna que con aspiraciones de integralidad se abocara a normar al teletrabajo ${ }^{2}$, sí podía observarse una mínima reglamentación por parte de la Superintendencia de Riesgos del Trabajo ${ }^{3}$ que en su resolución 1552/12 (B.O.A. de 14/11/2012) contempló una serie de obligaciones a cargo de la parte empleadora en materia de seguridad y prevención de riesgos. Por su lado, Espańa contaba con algunas previsiones en el anterior art. 13 de la Ley del Estatuto de los Trabajadores, pero centradas genéricamente en el trabajo a distancia lucían insuficientes para brindar soluciones a las específicas problemáticas planteadas por el teletrabajo ${ }^{4}$. A la par, no es ocioso acotar que en ambos países se concretaron programas pilotos sobre teletrabajo promovidos gubernamentalmente y algunos acuerdos fruto de la negociación colectiva. $Y$ respecto al país europeo, no cabe omitir la trascendencia del Acuerdo Marco Europeo sobre Teletrabajo5.

En rigor, el inmediato antecedente quizás se conecte con las medidas implementadas por los gobiernos a causa de la pandemia provocada por la COVID-19: ellas generaron que una considerable cantidad de trabajadoras y trabajadores pasaran a ejecutar las labores en sus lugares de residencia o aislamiento y por medios informáticos ${ }^{6}$. Tal forma de emprender el trabajo, con acen-

\footnotetext{
${ }^{1}$ En esos términos se lo caracteriza en la parte inicial del capítulo I de la exposición de motivos del Real Decreto-Ley y de la Ley 10/2021 y es confirmado en el art. 2 de dichos productos normativos.

${ }^{2}$ Si bien desde el año 1941 se encuentra vigente la ley 12.713 "Sobre trabajo a domicilio" (B.O.A. de 15/11/1941), ella lógicamente no contempla la nueva modalidad marcada por la utilización de medios tecnológicos, antes bien, recepta desde antaño la labor de las trabajadoras y los trabajadores en sus viviendas o locales elegidos -o en los de los talleristas- en la elaboración de artículos o mercaderías entregados por la persona empleadora, tradicionalmente vinculada con la confección de indumentaria textil. Por cierto, tampoco el Convenio 177 de la O.I.T. "sobre el trabajo a domicilio" (aprobado por la Argentina por Ley 25.800, B.O.A. de 2/12/2003) y la Recomendación 184 se ocupan del teletrabajo en sus precisas facetas.

${ }^{3}$ En su carácter de entidad autárquica en jurisdicción del Ministerio de Trabajo, Empleo y Seguridad Social de la Nación que tiene como función esencial controlar el cumplimiento de las normas de higiene y seguridad en el trabajo (conf. arts. 35 y 36 de la Ley 24.557 “de Riesgos del Trabajo", B.O.A. de 4/10/1995).

${ }^{4} \mathrm{Al}$ respecto, se destacaba la necesidad de normar las distintas complejidades que derivan de aquel carácter propio del teletrabajo afincado en la utilización de forma intensiva de las nuevas tecnologías informáticas y de la comunicación, ausente en el viejo art. 13 de la Ley del Estatuto de los Trabajadores; véase: QUINTANILLA NAVARRO, Raquel Yolanda, 2017. El teletrabajo: de la dispersión normativa presente a la necesaria regulación normativa europea y estatal futura. Oficina de la OIT para España [en línea]. Disponible en: https://www.ilo.org/madrid/fow/trabajo-y-sociedad/WCMS_548615/lang--es/index.htm [consulta: 11/11/2020].

${ }^{5}$ Suscripto en el año 2002 -y revisado luego en el 2009- por la Confederación Europea de Sindicatos, la Unión de Confederaciones de la Industria y de Empresarios de Europa, la Unión Europea del Artesanado y de la Pequeña y Mediana Empresa y el Centro Europeo de la Empresa Pública, tuvo como objetivo establecer un marco general a nivel europeo para las condiciones laborales de las personas que teletrabajan.

${ }^{6}$ En el caso argentino, el Ministerio de Trabajo, Empleo y Seguridad Social por resolución 279/2020 (B.O.A. de 1/04/2020) había señalado que las personas trabajadoras alcanzadas por el "aislamiento social preventivo y obligatorio" (medida estatal de tutela sanitaria que condujo a la población a resguardarse en sus hogares) quedaban dispensadas de concurrir al lugar de trabajo, pero que cuando sus tareas u otras análogas pudiesen ejecutarse desde el sitio de aislamiento debían establecer con el sujeto empleador las condiciones en que dicha labor sería realizada (art. 1). En el país europeo, es confirmado por el Real Decreto-ley 8/2020 (B.O.E. de 18/03/2020) que en su art. 5 otorgó carácter preferente al trabajo a distancia en el período de excepcionalidad sanitaria; además, da cuenta de ello el apartado III de la exposición de motivos del Real Decreto-ley 28/2020 y de la Ley 10/2021, allí se expresa “...El
} 
tuado carácter coyuntural y empujada por las reglas heterónomas impartidas por los Estados en respuesta urgente a la crisis sanitaria, y por ello no identificable plenamente con el teletrabajo ${ }^{7}$, hubo de darle a éste -sin embargo- un inédito protagonismo, tanto es así que de alguna manera fue el gran motor de la actividad normativa que culminó con las regulaciones que concitan la atención del presente estudio.

\section{Cotejo normativo}

\section{1. Ámbito de aplicación}

De suyo, que ambas legislaciones son aplicables a las relaciones laborales entabladas entre particulares, excluyéndose los vínculos de empleo público. En cada caso, ese dato surge del art. 2 de la Ley $27.555^{8}$ y del art. 1 y disposición adicional segunda del Real Decreto-ley 28/2020 y de la Ley 10/2021.

En este capítulo, la normativa del país europeo ciñe su aplicación a aquel trabajo a distancia que se desarrolle con carácter "regular", esto es: cuando "se preste en un periodo de referencia de tres meses, un mínimo del treinta por ciento de la jornada, o el porcentaje proporcional equivalente en función de la duración del contrato de trabajo" (art. 2 cit.). Complementariamente, tal vez haciéndose cargo de los numerosos supuestos que bajo ese rígido molde queden fuera del ámbito normativo, expresamente se ha facultado a la negociación colectiva a rebajar los referidos límites cuantitativos (disposición adicional primera, punto 2).

En lo que concierne al régimen argentino, con un contenido opinable a tenor de los confines que delimitan la misma competencia reglamentaria en la que pretendidamente se sustenta, el decreto que acompaña a la ley (art. 1 del Decreto 27/2021) indica que esta última no se aplicará en los casos en los que la labor se realice en establecimientos de clientes de la empresa a quienes preste servicios continua o regularmente, o ya, en una fórmula no exenta de imprecisión, en los casos en los cuales la prestación se efectúe "en forma esporádica y ocasional" -agrega- en el "domicilio de la persona que trabaja”, expresión final que entendemos exigua a poco de reparar en que el teletrabajo puede realizarse opcionalmente en otro lugar -fuera del establecimiento o centro laboral- distinto de aquel en el que se domicilia la persona que labora.

De todos modos, huelga decir que supeditado a que concurra la hipótesis de prestación de trabajo dirigido en favor de otra o de otro de conformidad con las disposiciones legales (la relación dependiente o subordinada), aquellas personas marginadas de los regímenes especiales por no cum-

teletrabajo se ha instalado en nuestro país como respuesta a las restricciones y medidas de contención de la pandemia aún vigentes, en un contexto legal caracterizado por la casi total ausencia de regulación específica. La generalización del teletrabajo en España, que trae su causa en las medidas adoptadas por las autoridades competentes para contener y frenar la expansión de la pandemia, se ha traducido en una suerte de desequilibrio de derechos y obligaciones entre empresas y personas trabajadoras, cuando menos. Se requiere de una norma que ayude a las partes empresarial y trabajadora a trasladar el carácter tuitivo del derecho del trabajo a la nueva realidad que se ha visto acelerada exponencialmente, como consecuencia de circunstancias exógenas e imprevisibles...".

${ }^{7}$ En este sentido, se ha precisado que en comparación con el teletrabajo en circunstancias normales, el teletrabajo durante la pandemia presenta más dificultades porque es obligatorio en lugar de voluntario, y a tiempo completo en lugar de la posibilidad de ejecutarlo parcialmente. OFICINA INTERNACIONAL DEL TRABAJO, 2020. El teletrabajo durante la pandemia de COVID-19 y después de ella - Guía práctica. Organización Internacional del Trabajo. Disponible en: https://www.ilo.org/wcmsp5/ groups/public/---ed_protect/---protrav/---travail/documents/publication/wcms_758007.pdf . [Consulta: 10/11/2020]

${ }^{8}$ Indirectamente en la Argentina, puesto que la ley en examen por medio de su art. $2^{\circ}$ dispone que sus normas habrán de incorporarse al cuerpo legislativo general, que es la Ley 20.744 comúnmente denominada Ley de Contrato de Trabajo (concretamente introduce el Capítulo VI nominado "Del Contrato de Teletrabajo” al Título III ““De las modalidades del contrato de trabajo”), que -por regla- no es aplicable al personal de la administración pública (art. 2 inc. a, ley cit.).

${ }^{9}$ Divisamos en la "ocasionalidad" un factor igualmente utilizado en el Convenio 177 de la O.I.T. para restringir el concepto de trabajador a domicilio (art. 1 inc. b). 
plir con los requisitos referidos no obstante permanecerán bajo la tutela del ordenamiento jurídico laboral (en los distintos firmamentos normativos: la Ley de Contrato de Trabajo y el Estatuto de los Trabajadores $)^{10}$.

\subsection{Definición del teletrabajo}

La ley laboral argentina (nuevo art. 102 bis que se incorpora a la Ley de Contrato de Trabajo) lo conceptualiza como un "contrato" y establece que se verificará siempre que la realización de actos, ejecución de obras o prestación de servicios en los términos de los arts. 21 y 22 de la Ley de Contrato de Trabajo" "sea efectuada total o parcialmente en el domicilio de la persona que trabaja, o en lugares distintos al establecimiento o los establecimientos del empleador, mediante la utilización de tecnologías de la información y comunicación”.

La normativa española expresa que el teletrabajo es una de las tantas modalidades que se agrupan bajo el "trabajo a distancia"; precisamente, es a partir de este último que lo define y regula en sus distintas aristas. Enlazando armónicamente los conceptos de su articulado, podría decirse que el teletrabajo se presenta como una "forma de organización del trabajo o de realización de la actividad laboral" en la que la tarea se presta en el domicilio de la persona trabajadora o en el lugar elegido por esta, durante toda o parte de la jornada, con carácter regular ${ }^{12}$, y lo que resulta decisivo para marcar la tipología: llevándose a cabo con "el uso exclusivo o prevalente de medios y sistemas informáticos, telemáticos y de telecomunicación” (art. 2, Real Decreto-ley y Ley antes cits.).

Ya sea adjetivándoselo como modalidad contractual, o bien, una forma de organización del trabajo, a pesar de sus matices las concepciones de ambas legislaciones comparten elementos troncales: tienen por objeto normar una actividad laboral dependiente ${ }^{13}$ que se ejecuta en el domicilio de la persona que trabaja o en otro distinto del centro empresario, durante toda o parte de la jornada (deslocalización respecto del centro de la empresa total o parcial) y mediante el empleo -gran rasgo distintivo del teletrabajo- de las llamadas "tecnologías de la información y comunicación" ${ }^{4}$.

\footnotetext{
${ }^{10}$ Con la mirada puesta en el articulado hispano, incluso se ha sostenido que le es aplicable al trabajo a distancia "ocasional" -o "no regular"- el principio de voluntariedad o de igualdad de trato, las reglas de protección integral de los riesgos del trabajo, como aquellas directrices referidas al resguardo de la intimidad, protección de datos, desconexión, entre otros institutos previstos en la normativa en análisis. En: GÓMEZ ABELLEIRA, Francisco Javier. La nueva regulación del trabajo a distancia. Valencia, Tirant lo Blanch, 2020, pág. 26.

${ }^{11}$ En dichos preceptos legales se define -respectivamente- al contrato de trabajo y a la relación de trabajo. El art. 21 reza: “... Contrato de trabajo. Habrá contrato de trabajo, cualquiera sea su forma o denominación, siempre que una persona física se obligue a realizar actos, ejecutar obras o prestar servicios en favor de la otra y bajo la dependencia de ésta, durante un período determinado o indeterminado de tiempo, mediante el pago de una remuneración. Sus cláusulas, en cuanto a la forma y condiciones de la prestación, quedan sometidas a las disposiciones de orden público, los estatutos, las convenciones colectivas o los laudos con fuerza de tales y los usos y costumbres...”. Mientras que el art. 22 dispone: “...Relación de trabajo. Habrá relación de trabajo cuando una persona realice actos, ejecute obras o preste servicio en favor de otra, bajo la dependencia de ésta en forma voluntaria y mediante el pago de una remuneración, cualquiera sea el acto que le dé origen...".

${ }^{12}$ Regularidad que se ha visto, según se ha edificado la ley, gravita en la estructura de su ámbito de aplicación.

${ }^{13} \mathrm{Al}$ respecto, hace décadas se enseńaba que en el trabajo a domicilio la falta de vigilancia del empresario sobre la persona trabajadora antes que evidenciar la ausencia de dependencia indica una mera debilitación de su contenido, pues el hecho que la/el dependienta/e no esté físicamente en el centro de trabajo no significa que se halle fuera del círculo organizativo y disciplinario del empresario, y-en lo que aquí más interesa- que en el teletrabajo on line la conexión con el ordenador central intensifica la dependencia. En: MONTOYA MELGAR, Alfredo, Derecho del Trabajo. Madrid, Ed. Tecnos, 2008, pág. 527.

${ }^{14}$ Entre muchas definiciones, recogemos aquella que indica que se trata de un "...conjunto de tecnologías que permiten la adquisición, producción, almacenamiento, tratamiento, comunicación, registro y presentación de informaciones, en forma de voz, imágenes y datos contenidos en señales de naturaleza acústica, óptica o electromagnética...”. Con cita de CAMPUZANO TOMÉ, véase: BAYÓN PÉREZ, Jessica y ZERBI, Anna. 2020. El teletrabajo: avances y retos dentro de la sociedad actual. Revista Internacional y Comparada de Relaciones Laborales y Derecho del Empleo. Ed. Adapt. [en línea] Disponible en: http://adapt.it/wp/wp-content/ uploads/2020/09/revista_n3_2020_def.pdf [consulta: 13/11/2020].
} 
Acaso, no sea ocioso mencionar que pueden hallarse nociones similares en el plano del derecho internacional del trabajo, entre otras, en el Tesauro de la Organización Internacional del Trabajo donde se ilustra con simplicidad que el teletrabajo es el trabajo a distancia (incluido el trabajo desde casa) en el que se emplean "instalaciones de telecomunicaciones y / o computadoras"

\subsection{Igualdad de derechos}

En lo que representa una de las directrices fundamentales de los regímenes, se estatuye la igualdad de derechos entre las personas que desarrollan el trabajo a distancia -en la especie: las "teletrabajadoras"- y aquellas que prestan servicios en el centro de trabajo de la empresa, llamadas "presenciales". En el supuesto argentino -como se adelantó- si bien no se contaba con un antecedente normativo específico, la previsión (presente en el art. 3 de la nueva ley) se amolda a la genérica regla de no discriminación y de igualdad de trato en la relación laboral que se desprende de los arts. 17 y 81 de la Ley de Contrato de Trabajo. En el país europeo la anterior redacción del art. 13 de la Ley del Estatuto de los Trabajadores (aprobado por el Real Decreto Legislativo 2/2015. B.O.A. de 24/10/2015.) ${ }^{16}$ contenía la fundamental regla en el ámbito del trabajo a distancia, receptada ahora en el art. 4 del reciente régimen y con un más completo y minucioso desarrollo que su par argentina ${ }^{17}$, mejorado, a su vez, con la ampliación de las específicas causas de discriminación que las empresas se encuentran obligadas a evitar, ya en el texto que trajo la Ley 10/2021 (art. 4.3).

Nada esclarece -y debió hacerlo- la ley $27.555^{18}$, pero esa igualdad de derechos y obligaciones debe predicarse en tanto sea posible según la fisonomía de la prestación, o como indica la norma española: "Las personas que desarrollan trabajo a distancia tendrán los mismos derechos que hubieran ostentado si prestasen servicios en el centro de trabajo de la empresa, salvo aquellos que sean inherentes a la realización de la prestación laboral en el mismo de manera presencial” (art. 4.1, primer párrafo del Real Decreto-ley 28/2020 y de la Ley 10/2021).

A nivel global, el principio se halla receptado con varias ramificaciones en el art. 4 del Convenio 177 de la Organización Internacional del Trabajo "sobre el trabajo a domicilio", instrumento que, ya citado en otras oportunidades, toca referir que no ha generado hasta el momento un significativo número de adhesiones (Argentina -hemos apuntado- se encuentra entre los pocos países -once- que lo han ratificado, no así España).

\subsection{Voluntariedad y reversibilidad}

\subsubsection{Voluntariedad}

Enarbolando un principio en común, las legislaciones prescriben que esta forma de trabajo a distancia debe ser acordada voluntariamente por escrito, pudiendo ser convenida inicialmente, o bien con posterioridad durante el desarrollo de un contrato típico o de prestación presencial. El esencial recaudo implica -por regla- la imposibilidad jurídica para cada uno de los sujetos de imponer uni-

\footnotetext{
${ }^{15}$ ORGANIZACIÓN INTERNACIONAL DEL TRABAJO, Tesauro. [en línea] Disponible en: https://metadata.ilo.org/thesaurus/-1359993413.html [consulta: 13/11/2020].

${ }^{16}$ Ahora, expresamente modificado por la Disposición final tercera punto uno del Real Decreto-Ley 28/2020.

${ }^{17}$ La norma del país americano únicamente declara la igualdad de derechos y obligaciones con quienes trabajan bajo la modalidad presencial y hace especial referencia -sin más- a la remuneración, que -dice- no podrá ser inferior a la que se perciba bajo la modalidad presencial.

${ }^{18}$ En el mismo sentido: FUNES DE RIOJA, Ignacio. Régimen legal del teletrabajo. La Ley. Buenos Aires, del 14/04/2021, 2.
} 
lateralmente la modalidad remota y anida en las legislaciones inspeccionadas en el art. 7 de la Ley $27.555^{19}$ y en el art. 5.1 del Real Decreto-ley $28 / 2020$ y de la Ley $10 / 2021$.

En sucinto paréntesis, es interesante mencionar que no contando por entonces con la novel legislación, el Tribunal Supremo español ya había enfatizado en el carácter voluntario para la operaria y el operario de la aceptación del teletrabajo, ello derivaba -sostuvo- de lo establecido en los arts. 1091, 1204 y 1256 del Código Civil (normas que versan sobre los efectos de las obligaciones enmarcadas lo contractual) ${ }^{20}$.

Retomando, todavía abiertamente se señala en la norma ibérica que el trabajo a distancia no puede ser impuesto en aplicación del art. 41 del Estatuto de los Trabajadores, disposición, ésta, que con diseño disímil al del régimen del contrato de trabajo argentino ${ }^{21}$ faculta a la dirección de la empresa a acordar modificaciones sustanciales de las condiciones de trabajo cuando existan razones de índole objetivas (económicas, técnicas, organizativas o de producción). Más aún, el vigor que en el específico esquema del Real Decreto-ley 28/2020 y de la Ley 10/2021 presenta la voluntariedad en el origen del acuerdo, pervive en su posterior etapa: en ambos casos expresa el art. 8.1 que la modificación de las condiciones establecidas en el acuerdo de trabajo a distancia (no solo las del contenido mínimo obligatorio apuntadas en el art. 7 del régimen) deberá ser objeto de convención escrita entre la empresa y la persona trabajadora; de este modo, como señala autorizada doctrina ${ }^{22}$, el precepto tiene la virtualidad de sustraer la hipótesis del régimen legal laboral general (en esencia: del ya citado art. 41) exigiendo ahora que cualquier tipo de alteración -sea o no sustancial- en la regulación de las condiciones del acuerdo requiera un pacto entre las partes.

No obstante lo que se viene diciendo, el precepto legal español establece que sus disposiciones referidas a la voluntariedad lo son "sin perjuicio del derecho al trabajo a distancia que pueda reconocer la legislación o la negociación colectiva” (art. 5.1. antes cit.). En este terreno es propicio recordar, ya que se revela como una suerte de excepción al principio -aquí, restringiendo el campo volitivo de la empresa-, lo dispuesto en el art. 34.8 del Estatuto de los Trabajadores que al consagrar en favor de quien trabaja el derecho a la conciliación de la vida familiar y laboral ${ }^{23}$ y facultarla a peticionar "las adaptaciones de la duración y distribución de la jornada de trabajo, en la ordenación del tiempo de trabajo y en la forma de prestación" incluye la potestad de solicitar algo que se aleja de lo concerniente a la ordenación de la jornada para ingresar en la mutación de la propia estructura contractual $^{24}$ : "la prestación de su trabajo a distancia", otorgando además un procedimiento específico para encarrilar jurisdiccionalmente la pretensión (aquel del art. 139 de la Ley 36/2011, B.O.E. de 11/10/2011). Tan fuerte herramienta, paradigma de un claro propósito de privilegiar la tutela

${ }^{19}$ Sin perjuicio que la modalidad del teletrabajo obviamente puede ser pactada al inicio de la relación (lo que es corroborado en la última parte del art. 8), la norma argentina alude únicamente a la voluntariedad que debe imperar en el "traslado" de quien trabaja en una posición presencial a la modalidad de teletrabajo. En otro orden, se exceptúa la concurrencia del requisito en "casos de fuerza mayor debidamente acreditada”.

${ }^{20}$ STS de 11 de abril de 2005 (Ro. 143/2004, Sala de lo Social).

${ }^{21} \mathrm{El}$ art. 66 de la Ley de Contrato de Trabajo lisa y llanamente expresa que la parte empresaria está autorizada a introducir cambios relativos a la forma y modalidades de la prestación del trabajo cuando no importen un ejercicio irrazonable de esa facultad, ni alteren modalidades esenciales del contrato, ni causen perjuicio material ni moral a la persona que trabaja.

${ }^{22}$ Así, PÉREZ DE LOS COBOS Y ORIHUEL, Francisco, La modificación de las condiciones de trabajo en el contrato de trabajo a distancia, En: PÉREZ DE LOS COBOS Y ORIHUEL, Francisco y THIBAULT ARANDA, Xavier (Dir.), El trabajo a distancia. Con particular análisis del Real Decreto-Ley 28/2020, de 22 de septiembre, Madrid, La Ley, 2021, págs. 179-196.

${ }^{23}$ Trascendente prerrogativa incorporada por el Real Decreto-ley 6/2019 (B.O.E. de 7/03/2019).

${ }^{24}$ Centrando la atención en esta prescripción, concordantemente se ha expresado que la nueva norma, al referirse a la forma de prestación, incluida la prestación de su trabajo a distancia, ha ampliado el objeto del derecho de adaptación de la ordenación del tiempo de trabajo, configurándose un "redimensionamiento del ámbito material que cuestiona su ubicación sistemática, lógica en su genética como precepto referido a la adaptación del tiempo de trabajo, pero ahora superada”. Es la opinión de PASTOR MARTÍNEZ, Albert, 2019. Las medidas laborales del Real Decreto-Ley 6/2019, de $1^{\circ}$ de marzo de medidas urgentes para garantía de la igualdad de trato y de oportunidades entre mujeres y hombres en el empleo y la ocupación. En: IUSLabor. Revista d'anàlisi de Dret del Treball [en línea]. Disponible en: https://doi.org/10.31009/IUSLabor.2019.i01.03 [consulta: 4/07/2021]. 
de un preciado bien jurídico como es la familia, se encuentra ausente en el programa normativo del país americano que -como se verá en párrafos posteriores- se circunscribe a establecer ciertas prerrogativas en favor de la persona que labora únicamente en lo que respecta a la distribución del horario de trabajo.

\subsubsection{Reversibilidad}

La reversibilidad, que en el marco del desarrollo del teletrabajo se traduce en la facultad de exigir el retorno a una preexistente modalidad de trabajo presencial, si bien está presente en los dos regímenes (art. 8 de la Ley 27.555 y art. 5.3 del Real Decreto-Ley 28/2020 y de la Ley 10/2021), en el argentino solo emerge reconocida -es lo que indica la literalidad de su texto- en favor de la persona que trabaja y no de ambas partes como acontece en el supuesto espańol, tampoco se alude en el primero a la posibilidad de que los sujetos puedan acordar sobre el punto; tales aspectos han sido de los más objetados en la legislación del país latinoamericano ${ }^{25}$. Pese a ello, el Decreto 27/2021 con mejor técnica y poniendo el foco en el complejo equilibrio que plantea la correlatividad de derechos y deberes del vínculo contractual, con indiscutible acierto ha ańadido a la regulación argentina la exigencia de que la solicitud de reversión que presente la trabajadora o el trabajador deba guardar una motivación "razonable y sobreviniente", asimismo, ha previsto un plazo prudencial para que la empresa pueda dar cumplimiento con lo peticionado (art. 8 Decreto cit.).

\subsection{Jornada}

\subsubsection{Conciliación horaria o flexibilidad}

Sin perjuicio de requerirse en los cuerpos normativos la necesidad de dejar constancia expresa -en documento escrito- de la jornada pactada (art. 4 de la Ley 27.555 y art. 7 inc. c del Real Decreto-ley y de la Ley en examen), en cada uno de ellos se introducen pautas de flexibilidad en el horario de trabajo.

Conforme lo observado, el art. 6 de la regulación argentina -en una regla, que objetable desde el principio de igualdad, no se ha previsto para las personas que trabajan de modo presencial- reconoce a quienes ejecutan sus labores por medio de esta especial modalidad el derecho a horarios compatibles o a interrumpir la jornada en relación con las tareas de cuidado de personas menores de trece ańos, con discapacidad o adultas mayores que convivan con ellos y que requieran asistencia específica. La normativa del país europeo -con más amplitud- expresa en su art. 13 que la persona que desarrolla el trabajo a distancia podrá flexibilizar el horario de prestación de servicios según lo establecido en el acuerdo de trabajo a distancia y la negociación colectiva, debiéndose respetar los tiempos de disponibilidad obligatoria y la normativa sobre tiempo de trabajo; además -como en

\footnotetext{
${ }^{25}$ En este sentido -y entre varios- pueden verse las opiniones de: CONFALONIERI (h.), Juan Ángel, Los teletrabajadores. Una categoría propia de los procesos de descentralización por descolocación del lugar de prestación de servicios, potenciada en la época de la COVID-19. Comentario a la ley 27.555. La Ley. Buenos Aires, Ed. Thomson Reuters, del 3/09/2020, 2; DE DIEGO, Julián, La ley transitoria de Teletrabajo 27.555 y sus proyecciones, reformas y reglamentación. La Ley. Buenos Aires, Ed. Thomson Reuters, del 3/09/2020, 11; y SANZ, Josefina, Una mala solución a un problema inventado. Reflexión sobre el proyecto de Ley de Teletrabajo aprobado en Diputados. El Teletrabajo en el Ordenamiento Jurídico Argentino. Volumen I, Buenos Aires. Ed. IJ Editores, 2020, obra colectiva en Ebook. [en línea]. Disponible en: https://ar.ijeditores.com/index.php?option=publicaciones [consulta: 11/11/2020]. Vale agregar que el diseńo argentino que rodea a la reversibilidad en el texto originario de la ley tampoco encuentra recepción o congruencia con el adoptado en otros países a nivel regional, ello puede constatarse tanto en el Decreto Supremo 4218 de Bolivia (pub. 14/04/2020), como en la Ley 13.467 de Brasil (pub. 14/07/2017), en la Ley 21.220 de Chile (pub. 26/03/2020); o en la Ley 30.036 de Perú (pub. 05/06/2013).
} 
parte se anticipó al hablar de la voluntariedad- en su art. 4.5 señala que, al igual que las trabajadoras y los trabajadores presenciales, quienes se desempeñan bajo esta modalidad gozan del "derecho de adaptación a la jornada” establecido en el -ya mencionado- art. 34.8 del Estatuto de los Trabajadores, a fin de que no interfiera el trabajo con la vida personal y familiar.

\subsubsection{Derecho a la desconexión digital}

Inserto en el art. 5 de la ley argentina y en el art. 18 del Real Decreto-Ley 28/2020 y de la Ley 10/2021 (con remisión parcial al art. 88 de la Ley Orgánica 3/2018, pub. en el Boletín Oficial del día 6/12/2018), en concreto, alude al derecho de quien teletrabaja a desconectarse de los dispositivos tecnológicos de comunicación con la persona empleadora fuera de la jornada laboral. Siendo una expresión del instituto de la jornada de trabajo, por las características propias del teletrabajo -en sustancia: el riesgo a la superposición o mutua interferencia que plantea entre lo laboral y lo personal- asume aquí fundamental importancia. Agudamente se ha recalcado que "...La línea que separa el tiempo de trabajo efectivo del tiempo de ocio y descanso, resulta cada vez, más delgada, lo que a la postre, provoca prácticamente que el empleado nunca desconecte del trabajo. Y ello es así porque las conocidas como Tecnologías de la Información y Comunicación (TIC) empujan a una disponibilidad horaria y locativa constante de los trabajadores, incluso, fuera de su horario laboral..." 26 .

Sin restarle su indiscutible valor, es claro que este derecho, lejos de recorrer un camino en solitario, se inserta en el plexo normativo que dota de singularidad al contrato de trabajo y en el que sobresalen los típicos deberes de conducta que le son tan característicos, signados por los mandatos de colaboración y solidaridad. Lo dicho se refleja en una valiosa previsión del sistema del teletrabajo en la Argentina, hablamos del art. 5 del Decreto 27/2021, que relativizando los alcances de la tajante regla de desconexión que consagra la ley reglamentada y mostrando que no nos hallamos frente a un derecho absoluto, admite la remisión de comunicaciones a la persona trabajadora fuera de la jornada laboral cuando la actividad de la empresa se realice en diferentes husos horarios, o bien, cuando resulte indispensable por alguna razón objetiva, aunque con la aclaración que aquella no estará obligada a responder sino hasta el inicio de la nueva jornada, salvo -por ejemplo- casos de accidentes o fuerza mayor, entre otras circunstancias excepcionales.

\subsection{Tutela a la intimidad de la persona que trabaja en dependencia y protección de datos}

Con proyección en dos derechos fuertemente emparentados, se resguarda a quien trabaja en su intimidad -en su esfera personal y familiar- y en la protección de sus datos (arts. 15 y 16 de la legislación argentina y art. 17 de la espańola ${ }^{27}$ ), en una distinción conceptual más marcada en el caso español, a influjo indudablemente de la jurisprudencia del Tribunal Constitucional quien ha ilustrado refiriendo que "...La función del derecho fundamental a la intimidad del art. 18.1 C.E. es la de proteger frente a cualquier invasión que pueda realizarse en aquel ámbito de la vida personal y familiar que la persona desea excluir del conocimiento ajeno y de las intromisiones de terceros en contra de su voluntad [...]. En cambio, el derecho fundamental a la protección de datos persigue

\footnotetext{
${ }^{26}$ TRUJILLO PONS, Francisco, 2020. El ejercicio del derecho a desconectar digitalmente del trabajo: su efectividad en las empresas. Revista de relaciones Laborales. Lan Harremanak [en línea]. Disponible en: https://doi.org/10.1387/lan-harremanak.21954 [consulta: 04/07/2021].

${ }^{27}$ Ello, sin dejar de ponderar que la materia había sido objeto de reglamentación mediante la incorporación del art. 20 bis de la Ley del Estatuto de los Trabajadores por la disposición final decimotercera de la Ley Orgánica 3/2018 (B.O.E. de 6/12/2018).
} 
garantizar a esa persona un poder de control sobre sus datos personales, sobre su uso y destino, con el propósito de impedir su tráfico ilícito y lesivo para la dignidad y derecho del afectado..."28.

Bajo tales principios, se faculta a quien tiene la titularidad de la empresa a establecer sistemas de vigilancia y control para verificar el cumplimiento por la persona trabajadora de los deberes laborales, pero resguardando la intimidad de ésta y con la participación "sindical" (art. 15 ley argentina), o bien en el caso español guardando la consideración debida a su "dignidad" y con la intervención de la "representación legal" del personal en la elaboración de los criterios de empleo de los dispositivos (arts. 17.3 y 22 del régimen), y teniendo en cuenta además -conforme hubo de agregarlo la Ley 10/2021 - las circunstancias personales de quien trabaja, "como la concurrencia de una discapacidad" (art. 22 cit.).

\subsection{Elementos de trabajo. Compensación de gastos}

Coinciden los cuerpos normativos en receptar el derecho de la trabajadora o el trabajador a que le sea proporcionado por la empresa el equipamiento y el soporte necesario para el desempeño de las tareas, debiendo asumir esta última los costos de instalación, mantenimiento y reparación, siendo que además, se prevé la compensación a la/el dependienta/e por eventuales gastos en los que pudiese incurrir (arts. 9 y 10 de la Ley 27.555 -y 9 del Decreto 27/2021- y arts. 7 incs. "a” y "b” y 11 y 12 del Real Decreto-Ley 28/2020 y Ley 10/2021). Particularmente, es interesante la disposición que incorpora la Ley 10/2021 al establecer el deber de la empresa de asegurarles a las personas trabajadoras con discapacidad -asunto se habrá advertido, que ocupa fundamental atención en la mentada legislación- que las herramientas de trabajo (equipos, etc.) resulten "universalmente accesibles" (art. 11 cit.).

Las previsiones lucen en un todo orgánicas con la labor por cuenta ajena y dirigida por otra persona que supone el trabajo subordinado, aquí, a distancia (conf. arts. 21 de la Ley de Contrato de Trabajo argentina y art. 1.1. de la Ley del Estatuto de los Trabajadores de España).

Como contracara, se coloca en la persona trabajadora el deber de cumplir con las condiciones e instrucciones de uso y de conservar las herramientas de trabajo (art. 9 de la ley argentina y art. 21 de la regulación española).

Puntualmente, en referencia a los desembolsos que demande el desarrollo del teletrabajo -que en ningún caso posee naturaleza salarial-, la normativa del país europeo contempla la cuestión con mejor especificación al establecer que en el acuerdo de trabajo a distancia debe haber un contenido mínimo y que dentro de él deben enumerarse los gastos que pudiere tener la persona que efectúa las tareas como la forma de cuantificación de la compensación (art. 7 inc. b). El punto es significativo, pues se vincula con la indemnidad patrimonial de la persona que trabaja a distancia, y en concreto, remite a la prohibición de colocarla en una situación de desventaja en relación con aquella que se desempeńa en el centro empresario. Dable es memorar que la Organización Internacional del Trabajo ya en el año 1996 y en el marco de un concepto más amplio como es el del "trabajo a domicilio" -según la definición inserta en el documento internacional-, había establecido en la Recomendación 184 la necesidad que las trabajadoras y los trabajadores a domicilio percibiesen una compensación por gastos relacionados con las labores, como los relativos al consumo de energía y de agua, las comunicaciones y el mantenimiento de máquinas y equipos (art. 16). Y ciertamente, el Acuerdo Marco Europeo sobre Teletrabajo, también hubo de afrontar el tema al señalar que si el teletrabajo se realiza regularmente "el empresario cubre los costos directamente originados por este trabajo, en particular los ligados a las comunicaciones" (ap. $7^{\circ}$ ).

${ }^{28}$ STC $292 / 2000$ de 30 de noviembre de 2000. 


\subsection{Derecho a la formación o capacitación}

Las normativas contemplan la exigencia a la persona empleadora de garantizar la formación o capacitación de las operarias y los operarios necesaria para el desarrollo de su actividad (art. 11 de la ley argentina y art. 9 de la normativa espańola), algo de indiscutible relevancia en el teletrabajo en razón del dinamismo y constante evolución a los que están sujetos los medios o tecnologías utilizadas en su ejecución.

\subsection{Derechos colectivos}

Reforzando la regla de igualdad de derechos descripta con anterioridad ${ }^{29}$, las legislaciones disponen que las personas que trabajen bajo esta modalidad a distancia gozarán de todos los derechos colectivos, en igualdad de condiciones con aquellas que se desempeñan en el centro de trabajo (arts. 12 y 13 de la Ley 27.555 y art. 19 del Real Decreto-Ley 28/2020 y de la Ley 10/2021).

\subsection{Riesgos laborales}

Por el lado del legislador argentino se divisa una mera y ligera encomienda normativa en materia de higiene y seguridad a la autoridad de aplicación de la ley ${ }^{30}$ (art. 14), a quien se le encarga adicionalmente la tarea determinar la inclusión de las enfermedades causadas por esta modalidad en el régimen legal de riesgos del trabajo ${ }^{31}$; junto a ello, en una previsión que indudablemente ha de traer sus dificultades, se expresa que los infortunios acaecidos "en el lugar, jornada y en ocasión del teletrabajo" se presumirán accidentes en los términos de la mencionada legislación de riesgos laborales.

El sistema español cuenta con un ropaje jurídico que ofrece un superior detalle (arts. 15 y 16 del Real Decreto-ley y de la Ley posterior). En él, luego de anunciarse -declamado como derecho de la persona- que le es aplicable al trabajo a distancia la protección que en la materia contiene la Ley 31/1995 "de prevención de Riesgos Laborales" (B.O.E. de 10/11/1995) y su normativa de desarrollo $^{32}$, se pone énfasis en que la función de evaluar y prevenir los riesgos en esta modalidad debe considerar aquellos que le son característicos, especialmente, atendiendo a los factores psicosociales, ergonómicos y organizativos y -conforme lo adiciona la Ley 10/2021- "de accesibilidad del entorno laboral efectivo". Y es que en efecto, es un razonamiento mayormente compartido por la comunidad jurídica internacional aquel que recalca que aspectos ergonómicos, la intensidad de la labor, sumado al debilitamiento de los límites entre el trabajo y la vida privada, y el menor tiempo de desplazamiento y aislamiento son factores especialmente identificados en la prevención de la salud y el bienestar de quienes teletrabajan ${ }^{33}$. Estos motivos, por otra parte, han justificado la imposición de un férreo límite porcentual en el trabajo a distancia realizado por menores (art. 3 y ap. IV noveno párrafo de la exposición de motivos del Real Decreto-Ley y de la Ley en examen).

\footnotetext{
${ }^{29}$ Ver ap. 2.3 del presente.

${ }^{30}$ Conforme el art. 18 de la ley, se trata del Ministerio de Trabajo, Empleo y Seguridad Social de la Nación, quien según el texto del art. 14 del Decreto 27/2021 habrá de desempeñar dicha función a través de la Superintendencia de Riesgos del Trabajo.

${ }^{31}$ Nos referimos a la ley 24.557 de Riesgos del Trabajo (citada inicialmente) que en su art. 6 inc. 2 remite a un listado de enfermedades consideradas profesionales y resarcibles dentro del marco del seguro allí previsto.

32 Entre otros instrumentos, ponderamos de valiosa utilidad las "disposiciones mínimas de seguridad y salud relativas al trabajo con equipos que incluyen pantallas de visualización” receptadas en el Real Decreto 488/1997 (B.O.E. de 23/04/1997).

${ }^{33}$ En este sentido: OFICINA INTERNACIONAL DEL TRABAJO, 2019. Trabajar en cualquier momento y en cualquier lugar: consecuencias en el ámbito laboral. Organización Internacional del Trabajo. [en línea]. Disponible en: https://www.ilo.org/wcmsp5/ groups/public/---ed_protect/---protrav/---travail/documents/publication/wcms_712531.pdf [Consulta: 17/11/2020].
} 
Dentro de la normativa ibérica, dada su singularidad, merece ponerse de resalto el valioso intento de acoplar el debido resguardo de la esfera de privacidad de la persona que trabaja con la facultad y el deber de la empresa de informarse de los riesgos que pueden presentarse, ya que prevé que si la trabajadora o el trabajador se negase - no otorgase el necesario permiso- a recibir una visita de inspección, la actividad preventiva por parte de la empresa podrá efectuarse a partir de la información recabada de la persona trabajadora según las instrucciones del servicio de prevención (art. 16.2 in fine) $)^{34}$.

\subsection{Espacio de la negociación colectiva}

Incuestionablemente, el aludido mecanismo constituye un engranaje clave en la ardua tarea de acomodar la novedosa figura a los diversos sectores del universo laboral, y más precisamente, a la particular realidad de cada empresa; si el diálogo social siempre es un signo saludable en las relaciones de trabajo, aquí se vislumbra con acentuada nitidez.

El razonamiento es recogido en la exposición de motivos que acompaña a la ordenación española cuando destaca la necesidad de acudir a la negociación colectiva como "instrumento imprescindible para completar la normativa aplicable en cada uno de los sectores específicos, estableciendo criterios propios" (apartado IV, segundo párrafo), a su vez, en su disposición adicional primera cuando se enuncian los contenidos a abordar por los convenios colectivos.

Y en sintonía, se observa fácilmente que en no pocos puntos las legislaciones dejan en manos de los sujetos de derecho colectivo la regulación de múltiples aspectos del teletrabajo, un explícito reconocimiento al peso de la negociación colectiva entre las fuentes del derecho del trabajo. Así, por ejemplo, en lo relacionado con el propio cambio de la modalidad, igualmente, en materia de compensación de gastos por el uso de elementos necesarios para el teletrabajo (respectivamente: arts. 8 y 10 de la Ley 27.555 y arts. 5.3 y 12.2 del Real Decreto-Ley 28/2020 y de la Ley 10/2021).

\section{Dificultades que plantea la implementación de la modalidad}

En los últimos tiempos la promoción del teletrabajo ha sido acompañada de innumerables argumentos orientados a magnificar sus méritos. Empero, sin negar sus bondades, nos encontramos ante una concepción en el modo de organizar el trabajo que de cara a su ejecución sugiere una amplia gama de puntos conflictivos. Vayan como preludio a la clausura de la presente colaboración algunas reflexiones al respecto.

Por una parte observamos algo que es de toda obviedad: el teletrabajo está sujeto a ser implementado exclusivamente en las actividades que puedan desarrollarse con el empleo de las tecnologías de la información y la comunicación, básicamente, a través de Internet. Esto trae consigo la necesidad de contar con puestos de empleo que encajen en ese sistema y con un soporte tecnológico -fundamentalmente conectividad- altamente eficiente, condiciones que en varias zonas de las geografías que nos ocupan difícilmente puedan cumplirse ${ }^{35}$. Asimismo, reclama una constante capa-

\footnotetext{
${ }^{34}$ Se ha dicho -en una reflexión que compartimos- que se trata de una regla sensata en la que de algún modo se manifiesta que el gran problema de la prevención en el teletrabajo no es tanto el entorno físico cuanto el psicosocial, y que es en este segundo en el que deben poner cada vez más el foco las evaluaciones de riesgos y la planificación de la actividad. En: GÓMEZ ABELLEIRA, Francisco Javier, 2021. Real Decreto-Ley 28/2020, de 22 de septiembre de Trabajo a distancia. Ars Iuris Salmanticensis. [en línea]. Disponible en: https://revistas.usal.es/index.php/ais/article/view/26626/26025 [consulta 5/07/2021].

${ }^{35}$ Aludiendo a las medidas que muchas empresas tuvieron que tomar como consecuencia de las decisiones gubernamentales motivadas por la pandemia a partir del año 2020, mundialmente la O.I.T. ha estimado que cerca del 18 por ciento de los trabajadores tienen ocupaciones que son adecuadas para realizar desde casa (desde ya, refiriéndose a las que utilizan la tecnología de la información
} 
citación, y en la actualidad, un especial reto para las trabajadoras y los trabajadores de más elevada edad. Todo esto va ajustando los contornos de los espacios de aplicación fáctica de la modalidad, que consecuentemente, en modo alguno enseña un semblante con visos de universalidad.

Quizás, el mayor cúmulo de obstáculos se vincule con el peculiar entorno en el que se desarrollan las labores, generalmente el domicilio de la persona que trabaja. En alguna medida oculto de los servicios de inspección laboral, el teletrabajo ha de representar renovados esfuerzos tendientes a combatir el trabajo informal o clandestino y a controlar y prevenir eficazmente los riesgos laborales, que ahora asumen remozados perfiles. Y desde luego, cuestiones como la difícil amalgama que acontece entre las labores y la vida familiar, la llamada fatiga informática (todo ello vinculado con la desconexión digital, claro) y la protección de la privacidad de la operaria y del operario, conforman y fortalecen el abanico de complejidades. A ello se suma la problemática que gira en torno a los costos o gastos que demanden las labores, y en particular, a su determinación bajo pautas más o menos estables. Por otro lado, aunque con el mismo prisma crítico, el flujo y calidad de la comunicación son elementos también susceptibles de quedar expuestos a un proceso de deterioro a raíz de la distancia física de los sujetos involucrados en la prestación y dirección del trabajo.

Sin pretensión de agotar las diversas apreciaciones que podrían caber en el punto, desde otro costado, muchas de estas cuestiones han tratado de ser subsanadas en las normativas cotejadas, aunque en ciertos casos retaceando significativamente ciertas potestades de la persona empleadora, y así, quitándole atractivo a la modalidad, al menos, para quien detenta la titularidad de la organización productora de bienes o prestadora de servicios.

\section{Conclusiones}

Como resultado de años de experiencia en la implementación del teletrabajo, aunque estimulados por el inesperado desafío que trajo la pandemia causada por la COVID-19, los regímenes trazados en ambas latitudes -obviamente, siempre perfectibles- han confluido en reforzar un concreto marco tutelar para las personas que trabajan inmersas en esta moderna forma de organizar la labor fuera de los lindes geográficos de la empresa. Con la suprema finalidad protectoria del derecho del trabajo, las legislaciones comparadas muestran un entramado normativo que responde a una misma estructura, la cual, erigida sobre el principio de igualdad con los trabajadores tradicionales o presenciales, aborda ahora los institutos laborales con un renovado enfoque moldeado al singular escenario que conlleva esta clase de trabajo y en el cual sobresalen aquellos sensibles asuntos que rodean a la privacidad de la persona que trabaja, a la conciliación con su vida familiar y -en fin- al resguardo de su integridad psíquica y física. Con ello, una delicada tensión con las facultades y atributos de la persona empleadora termina conformando el complejo contexto que desafía a la promoción y expansión de la figura.

Con todo, es incuestionable que las relaciones de empleo avanzan velozmente hacia nuevas formas de ejecución signadas por el uso de tecnologías y apartadas del tradicional perfil que durante décadas caracterizó a la relación de trabajo dependiente; de una porción de esta realidad se ocupan las regulaciones descriptas, de allí su decisiva trascendencia de cara al futuro de los vínculos laborales.

y las comunicaciones) y residen en países que cuentan con la infraestructura necesaria para ello. En: OFICINA INTERNACIONAL DEL TRABAJO, 2020. Guía para empleadores sobre el trabajo desde casa en respuesta al brote de la COVID-19. Organización Internacional del Trabajo. [en línea]. Disponible en: https:/www.ilo.org/wcmsp5/groups/public/---ed_dialogue/---act_emp/documents/publication/wcms_747014.pdf [consulta: 7/07/2021]. 